\title{
Neurobiology of Pain in Children: An Overview
}

\author{
Alberto Loizzo $^{1}$, Stefano Loizzo $^{1}$ and Anna Capasso*,2 \\ ${ }^{1}$ Istituto Superiore di Sanita', Roma, Italy; ${ }^{2}$ Department of Pharmacology, University of Salerno, Italy
}

\begin{abstract}
The evaluation of pain in the newborn and the infant is difficult because pain is mainly a subjective phenomenon. Until a few years ago, several myths persisted. First, the myth that children, especially infants, do not feel pain the way adults do, therefore there is no untoward consequences for them. Second, lack of assessment and reassessment for the presence of pain. Third, misunderstanding of how to conceptualise and quantify a subjective experience. Fourth, lack of knowledge of pain treatment. Fifth, the notion that addressing pain in children takes too much time and effort, in ultimate analysis resulting in wasting time. Sixth, fears of hidden -and not easy to diagnose or prevent- adverse effects of analgesic medications, including respiratory depression and addiction. Finally, from a conceptual point of view, high thresholds of pain in neonates and infants were considered to be present by natural character, and useful in protecting infant from pain during birth and transit through the narrow vaginal channel.
\end{abstract}

The present review is focused on the description of different theories on the pain pathogenesis in children.

\section{INTRODUCTION}

Prematures, neonates and older children have highly developed neuroanatomical and neurohumoral structures, and can feel pain at least as adults do. Moreover, from research investigation performed in both children and in laboratory animals, we know that in these phases of life several components of the nervous, endocrine and other systems are still under a critical process of "programming". In laboratory animals acute strong painful procedures, or even mild repeated procedures as some pain episodes are (e.g., repeated injections), may upset for long time or permanently some organs programming and functions, and partly similar effects were observed in the clinical practice $[1,2]$. Therefore, the reasons for preventing and alleviating any forms of sufference to children appear to go far beyond the immediate target of avoiding pain, fear and distress. Sometimes, health structures show little understanding of adequate recognizing and facing problems related to children pain. Therefore, at least two priorities appear to exist in this field: First, educational priority. Training programmes for health-care workers should contain essential guidelines for relieving pain in children. Second, organizative priority. The staff of every hospital and cancer unit should include individuals with expertise in pain management. Integrated organizative units for palliative care should be finally recognized as an integral part of severe health problems care (e.g, cancer) in children.

Quite recently, all these statements were discussed and abated from different points of view. Anatomic and physiologic nociceptive pathways, although still developing, are in place in premature neonates as young as at 26 weeks of gestation, and several peripheral and central nervous system structures involved in nociception develop during the second and third trimester of gestation; moreover, although myelinization has not been fully estabilished by this time, it will

*Address correspondence to this author at the Department of Pharmacology, University of Salerno, Italy; Tel: +39-089-969602; Fax: +39-089-969744; E-mail: annacap@unisa.it only result in lesser speed of nociceptive transmission when compared to adult. Such reduction of information processing, however, is fully compensated by the shorter length of nerve layers to pain-modulating center in the central nervous system (CNS) [3-5]. Also synthesis of most neurotransmitters involved in pain sensitivity and modulation occurs early in human development, for example substance P or Betaendorphin are produced as early as at the $15^{\text {th }}-20^{\text {th }}$ weeks of gestation [6,7]. Therefore, although no neonates or infants can describe their pain sensitivity in current language, we know that most of their anatomical and neurochemical structures at these ages can produce stressful and unpleasant effects as strong and persistent as they do in other ages of life, and perhaps even more. Often, newborns are exposed to pain experiences such as blood sampling, immunization, vitamin $\mathrm{K}$ injection, or circumcision without receiving adequate analgesia or sedation procedures. These and other painful experiences should be avoided whenever possible. During the last few years both clinical and preclinical evidences were produced to better understand long-term effects induced by early stressful procedures, and these effects can represent the "memory" of pain. For example, circumcision performed at, or shortly after birth without analgesic procedures alters the infant response to successive pain, evaluated during vaccinations shots performed a few months later [8]. Moreover, other studies showed that 18-month-old former prematurelyborn extremely low birth weight infants, who spent the first few weeks of their life in neonatal intensive care units, were rated by their parents as much less behaviourally sensitive, compared to their term-born normal birth weight peers [9]. These data were confirmed by others [10].

Even stronger and more detailed evidences were produced by experimental laboratory investigation. Information collected from experimental animals showed that even mild but repetitive neonatal painful experiences (such as the one caused by a needle puncture) may cause long-term or permanent alterations of pain sensation, through interference with mechanisms connected to the developmental plasticity of the immature brain, in particular the plasticity of some neuro- 
chemical structures, as for example the opioid receptors sensitivity $[11,12]$. In fact, these stressful procedures administered within a critical window of increased sensitivity of biochemical structures to environmental changes, during specific structure synthesis periods in the developing brain, named "critical periods" of development may produce longterm or permanent alterations of said structures or functions. Moreover, effects of repetitive pain procedures coupled to repeated brief-lasting maternal separation during lactation period in rodents go far beyond pain sensitivity alteration. Rodent pups which in the neonatal period are exposed to these slight stressful procedures (daily saline subcutaneous injection plus 10 minutes deprivation from mother, up to weaning), display as adults a variety of behavioural, metabolic, hormonal and physiologic alterations. For example, they show enduring alterations of the immune system, consistent increase of body weight and upsetting of visceral fat distribution, accompanied by alteration of glucidic and lipidic metabolic parameters, alteration of hypothalamuspituitary-adrenal axis hormones feedback control mechanisms, and alterations of brain hippocampus neurophysiological parameters, indicating chronic derangement of brain plasticity modulation mechanisms [13-15] Table 1. Ruda et al. [16] studied a model of long-term effects of neonatal pain based on intraplantar hindpaw injection of complete Freund's adjuvant, and showed that when adults, in these rats which underwent further inflammation, the dorsal horn of the spinal cord on the side ipsilateral to the site of the previous neonatal inflammation, expressed significantly higher density of Fos-immuno-reactive neurons as compared to that on the contralateral side. Therefore, animal experiments are of great help in the understanding that children's sensitivity

Table 1. Types of Pediatric Pain

\begin{tabular}{|l|}
\hline Acute pain \\
\hline Procedure-related pain \\
\hline Peri-operative pain \\
\hline Burns \\
\hline Trauma \\
\hline Acute illness \\
\hline Cancer pain \\
\hline Tumor-related pain \\
\hline Therapy-related pain \\
\hline Chronic non-malignant pain \\
\hline Headaches \\
\hline Juvenile rheumatoid arthritis \\
\hline Chronic abdominal pain \\
\hline Haemophilia \\
\hline Sickle cell disease \\
\hline Chronic debilitating diseases \\
\hline Reflex sympathetic dystrophy \\
\hline
\end{tabular}

(modified from Gaukroger, 1991) [23]. to pain, and to pain-inducing procedures, should be viewed with greater attention by our mind, not only for the immediate elimination or assuaging pain and suffering whenever possible, but also for attenuating long-term or permanent consequences in the adult's life, possibly induced by stress and cascade consequences triggered by pain.

\section{TYPES OF PAIN IN CHILDREN}

Neurobiology of pain in children has peculiar developmental aspects; repeated or strong pain experiences may include stress-induced hormonal derangements which may produce prolonged structural and functional alterations in pain pathways that can last into adult life [17, 18]. Besides, most types of pain in children can be classified under the same taxonomy as adults, with differences in the relative prevalence and incidence of the various types [19-21]. Although pain classes are not diagnoses, categorizing pain helps guide treatment. Several systems for classifying pain exist. These include multidimensional classification systems, such as the IASP Classification of Chronic Pain [22] and a variety of systems based on a single dimension of pain experience. Of the latter systems, those based on pain duration (i.e., acute v/s chronic pain) and underlying pathophysiology i.e., nociceptive v/s neuropathic pain) are used most often.

Epidemiological data have been produced, but usually these are related to specific information. An example of data is added in the following Box 1:

Over one-third of school-age children will sustain injuries severe
enough to be treated by a doctor or nurse. The yearly costs have been
estimated to be 1.8 billion US\$ [24]
Traumatic injuries occur in more than 20 million US children each
year, and are the leading source of death in children over the age of 1
year [25]
Prevalence of children who ever experienced toothache ranges from 5
to $33 \%$ [26]
Headache in pediatric population is substantially underdiagnosed.
Studies indicate an overall prevalence of 8 up to $60 \%$ in various chil-
dren and adolescent populations [27]
Accurate prevalence of severy ill children with life-limiting condi-
tions in need of palliative care is not available, but figures are tending
to converge on 10 per 10000 children aged $0-19$ per annum [28]

Box 1.

\section{PAIN ASSESSMENT}

Infant pain assessment is not universally standardized. Several specialists and clinicians associations insist on a concept of pain which is also comprehensive of a wider vision of children's health and environment control. This concept was well summarized in the title of the paper "Prevention and management of pain and stress in the neonate" [29], and includes two of the main priciples in this field. The first is that pain must be prevented in each of its various aspects whenever possible. The second, that pain is a strong stressful procedure, and is accompanied and followed (and often preceeded as in the case of procedural pain) by a constellation of behavioural and pathophysiologic reactions inside the organism (Table 2). 
Table 2. Markers Used to Indicate Pain in Neonates

\begin{tabular}{|l|}
\hline Cardiorespiratory \\
\hline Increase in heart rate \\
\hline Increase in blood pressure \\
\hline Increase in respiratory rate \\
\hline Fall in trancutaneous oxygen concentration \\
\hline Sweat gland \\
\hline Increase in palmar sweating \\
\hline Increase in electrical conductance of the skin \\
\hline Hormonal \\
\hline Increased plasma concentrations \\
\hline Cortisol \\
Catecholamines \\
\hline Renin activity and aldosterone \\
\hline Growth hormone \\
\hline Glucagon \\
\hline Suppression of insulin secretion \\
\hline Behavioural \\
\hline Changes in facial expression \\
\hline Onset and duration of crying (or in some cases, stopping of crying) \\
\hline Flexor withdrawal of limb \\
\hline
\end{tabular}

(Modified from Chiswick, 2000) [30].

Consequences of Pain in Infants

\begin{tabular}{|c|c|}
\hline \multicolumn{2}{|c|}{ Immediate effects } \\
\hline 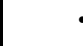 & Fear \\
\hline - & Irritability \\
\hline - & Disturbance of sleep and wakefulness state \\
\hline$\bullet$ & Increased oxygen consumption \\
\hline$\bullet$ & Ventilation-perfusion mismatch \\
\hline & Diminished nutrient intake \\
\hline & Increased gastric acidity \\
\hline \multicolumn{2}{|c|}{ Short term effects } \\
\hline$\bullet$ & Impaired emotional bonding \\
\hline$\bullet$ & Altered immunological function \\
\hline$\bullet$ & Delayed healing \\
\hline & Enhanced catabolism \\
\hline \multicolumn{2}{|c|}{ Long term effects } \\
\hline$\bullet$ & Alteration in response to subsequent painful experience \\
\hline$\bullet$ & Developmental retardation \\
\hline$\bullet$ & Memory of pain \\
\hline
\end{tabular}

(Modified from Mathew and Mathew, 2003) [31].
Because of the varying capabilities of communication, age-appropriate pain assessment tools are needed to facilitate accurate appraisal, i.e., in neonates, infants, toddlers, children. The three major modalities to pain assessment are: selfreports, behavioural observation, and monitoring of physiological parameters [32-37].

Pain can be assessed using self-report, because pain is a subjective experience. This method is to be applied in the case of mature children. Children have to accurately report on the location, sensory quality, intensity, affective elements and tolerability of pain. Because of the general skepticism of self-reports of pain from children, health care professionals sometimes tend to depreciate the validity of a child's pain complaints. These however may be of the greatest help [3237].

When communication is not possible, for children who are too young to understand the use of self-report scales, and children with cognitive impairment and/or physical handicaps, is necessary to resort to behavioural observation. Behavioural responses to pain change with the age and often with the type of pain (e.g., acute versus chronic), and follow a developmental trend. Therefore, several behavioural and physiological measurement tools were developed to assess pain in infants and nonverbal children; most useful parameters are: vocalization/ verbalization, facial expression, body language, and emotional state. The reliability and validity of behavioural observations are highest when the pain being measured is short in duration and acute in nature, such as pain associated with medical procedures. Facial expression has been found to be one of the most consistent indicators of pain. Components include brow bulge, eye squeeze, nasolabial furrow, open lips, vertical stretch mouth, horizontal stretch mouth, lip purse, taut tongue, and chin quiver [3237].

Parents/caretakers are the most consistent persons caring for a child and usually know what behaviors signal pain and what measures may comfort their child. Parents should be encouraged to participate in their child's pain assessment and management. This participation will not only benefit the child, but also give them a sense of control and help [32-37]. Children's pain and distress can be evaluated with the aid of objective physiological measures. Those parameters that have been tested as pain measures include heart rate, respiration rate, blood pressure, palmar sweating, cortisol levels, vagal tone, and endorphin concentrations. Other physiologic responses to pain include pupil dilation, flushing or pallor, nausea, and decrease in oxygen saturation. Many of these parameters have been incorporated into behavioral scales to form a more comprehensive assessment in infants and nonverbal children [38, 39]. 2.

Frequently used assessment scales include those in Box

Procedural pain (e.g., bone marrow biopsies, lumbar punctures or wound care and so on) is usually brief and can be a daily occurrence. These encounters, despite their brevity, can be traumatic. To prevent suffering, multiple modalities may be required. Current considerations suggest the implementation of imagery and distraction, since these techniques have been shown to be effective in children. The use of topical analgesics lessens the trauma of many procedures, 


\begin{tabular}{|c|c|}
\hline \multicolumn{2}{|c|}{ Based on Behavioural Change } \\
\hline$\bullet$ & Neonatal Facial Coding System (NFCS) \\
\hline & Infant Body Coding System (IBCS) \\
\hline & Neonatal Infant Pain Scale (NIPS) \\
\hline & Pain assessment in Neonates (PAIN) \\
\hline & Liverpool Infant Distress Scale (LIDS) \\
\hline & Modified Behavioural Pain Scale \\
\hline & Children's Hospital of Eastern Ontario Pain Scale (CHEOPS) \\
\hline & Neonatal assessment of Pain Inventory (NAPI) \\
\hline & Behavioural pain score \\
\hline & Clinical scoring system \\
\hline \multicolumn{2}{|c|}{ Combination of physiological and behavioural changes } \\
\hline & $\begin{array}{l}\text { CRIES (i.e., crying, change in transcutaneous oxygen satura- } \\
\text { tion, heart rate, blood pressure, facial expression and alteration } \\
\text { in sleep pattern). }\end{array}$ \\
\hline & Pain Assessment Tool (PAT) \\
\hline & Premature Infant Pain Profile (PIPP) \\
\hline$\bullet$ & Scale for Use in Newborns (SUN) \\
\hline$\bullet$ & COMFORT Score \\
\hline
\end{tabular}

(Modified from Mathew and Mathew, 2003) [31].

\section{Box 2. Pain Assessment Scales In Infants}

and the affective interaction with mother may prevent or attenuate some sequelae of stressful procedures. Sedation units afford safe completion of procedures with minimal duress for the child.

An increase in pulmonary artery pressure and an increase in the level of stress hormones such as ACTH, adrenaline, noradrenaline, corticosteroids, glucagon and aldosterone is seen when painful stimuli are inflicted upon neonates undergoing surgery without sufficient analgesia Table $\mathbf{3}$.

\section{PHARMACOLOGICAL INTERVENTION}

Analgesic drugs to be used in children are the same as for adults, and are administered using analogous procedures, but in the prevention and management of pediatric pain there are some important differences and general rules. The preferred administration routes are oral and rectal. Pain caused by intravenous and subcutaneous or intramuscular injection may be alleviated through the use of topical analgesic ointment. Pain should be prevented whenever possible, and in case of chronic pain analgesics should be administered according to a time programming, and not as needed. This approach saves children from suffering, requires lower doses of analgesic and lowers the possibility of tolerance effects. In the Box 3 some recommendations for pain treatment are reported.

The "analgesic ladder" for pain management proposed by the WHO [40], consists of a three-steps approach to pain treatment. Pain is classified as mild, moderate or severe, and analgesic choices are adjusted accordingly. The sequential use of analgesic drugs is based on the child's level of pain, and the first step in controlling mild pain is a non-opioid analgesic. If pain persists, an opioid for mild to moderate pain should be given together with non-opioid drug, if appropriate, for supplementary analgesia (step 2). When a weak opioid combined with a non-opioid fails to provide relief, an opioid for moderate to severe pain should be substituted (step 3). Morphine is the drug of choice in this instance. Again, non-opioid analgesics may be continued, and adjuvant drugs may be given for specific indications, according to the following scheme:

1) Non-steroidal anti-inflammatory drugs (NSAIDS) and paracetamol, with or without adjuvant drugs. Most common uses include acute pain, peri-surgical pain, headache, musculo-skeletal conditions. Most common

Table 3. Markers Frequently Used to Indicate Pain in the Neonate

\begin{tabular}{|c|c|c|c|c|}
\hline & $\begin{array}{l}\text { Premature Infant Pain Pro- } \\
\text { file }\end{array}$ & $\begin{array}{l}\text { Neonatal Facial Coding } \\
\text { Scale (NFCS) }\end{array}$ & $\begin{array}{l}\text { Neonatal Infant Pain } \\
\text { Scale (NIPS) }\end{array}$ & CRIES Score \\
\hline Variables assessed & $\begin{array}{l}\text { Gestational age Behaviour } \\
\text { Heart rate } \\
\text { Oxygen saturation } \\
\text { Brow bulge } \\
\text { Eye squeeze } \\
\text { Nasolabial furrow }\end{array}$ & $\begin{array}{l}\text { Brow bulge } \\
\text { Eye squeeze } \\
\text { Nasolabial furrow } \\
\text { Open lips } \\
\text { Stretch mouth } \\
\text { Lip purse } \\
\text { Taut tongue } \\
\text { Chin quiver } \\
\text { Tongue protrusion }\end{array}$ & $\begin{array}{l}\text { Facial expression } \\
\text { Cry } \\
\text { Breathing patterns } \\
\text { Arms } \\
\text { Legs } \\
\text { Arusal condition }\end{array}$ & $\begin{array}{l}\text { Crying } \\
\text { Requires increased oxygen admini- } \\
\text { stration } \\
\text { Increase of vital signs } \\
\text { Expression } \\
\text { Sleeplessness }\end{array}$ \\
\hline
\end{tabular}


- Pain in children is often unrecognized and undertreated, particularly in neonates. At any ages prematures, neonates and children do feel pain, and require analgesia as adults do

- If a medical procedure is painful in adults, it must be considered painful in children

- Newborns may experience a greater sensitivity to pain, and are much more susceptible to the long-term effects of pain, compared to older children and adults

- Adequate treatment of pain may be associated with decreased clinical complications and decreased mortality

- The appropriate use of pharmacological devices, associated to non pharmacological tools, prevent, reduce or eliminate pain in most clinical situations

- Sedation should be administered with care: it may, or it may not alleviate pain, but may mask children's behavioural response to pain

- Clinical units should develop written guidelines and protocols for the managements of pain in neonates and children

(Modified from Anand et al. 2001) [33].

Box 3.

substances, and recommended doses per os are: ibuprofen $(5-10 \mathrm{mg} / \mathrm{kg}$ every $6-8 \mathrm{~h})$; diclofenac $(1 \mathrm{mg} / \mathrm{kg}$ every 6-8 h); naproxen (5 $\mathrm{mg} / \mathrm{kg}$ every $8-12 \mathrm{~h})$; paracetamol (10-15 mg/kg, every 6-8 h). Paracetamol has scarce or no gastrointestinal or haematological side effects, but lacks anti-inflammatory activity.

2) Weaker opioids, with or without adjuvant drugs or NSAIDS. Most common substances are: codeine (0.5$1 \mathrm{mg} / \mathrm{kg}$ every 3-4 $\mathrm{h}$ for children over 6 months of age); hydrocodone $(0.2 \mathrm{mg} / \mathrm{kg}$ every $3-4 \mathrm{~h})$; oxycodone $(0.2 \mathrm{mg} / \mathrm{kg}$ every $3-4 \mathrm{~h})$, all given per os.

3) Strong opioids, with or without non-opioids and adjuvant drugs. Morphine recommended oral dose is 0.3 $\mathrm{mg} / \mathrm{kg}$ every 3-4 h (parenteral $0.1 \mathrm{mg} / \mathrm{kg}$ ); buprenorfine recommended parenteral dose is $0.004 \mathrm{mg} / \mathrm{kg}$ every 6-8 h). Fentanyl, usual iv or sc starting dose 0.5-2 micrograms/kg per $\mathrm{h}$ as continue infusion.

Adjuvant medication that are used in conjunction with analgesics often potentiate their analgesic effect. These include antihistamines (diphenhydramine, hydroxyzine, indicated for opioid-induced pruritus, nausea); tricyclic antidepressants (imipramine, amitriptyline, indicated for neuropathic pain, insomnia); anticonvulsants (gabapentin, carbamazepine, indicated for neuropathic pain, especially shooting or stabbing pain); psycostimulants (methylphenidate, amphetamine, indicated for opioid-induced somnolence, potentiation of opioid analgesia); corticosteroids (prednisone, dexamethasone, for headache from raised intracranial pressure, spinal or nerve compression, widespread metastases), and others. Procedural pain may be prevented with local analgesia, or when required with a combination of drugs which includes an anxyolitic (e.g., midazolam, lorazepam), with an opioid (e.g., fentanyl). In operating rooms or emergency rooms general anesthetic agents can be used (e.g., ketamine, usually administered in combination with atropine and midazolam, to prevent secretions and spasms). Other agents are propofol, or inhalation agents as nitrous oxide.

Several studies have shown the efficacy of cognitivebehavioural therapy interventions for decreasing anxiety and distress related to procedural pain in children [41, 42].

\section{PAIN AND GENDER}

Unfortunately, too often differences between males and females are not considered in laboratory research and in clinical practice, and instead are either ignored or statistically averaged. It is no longer controversial to suggest that there may be important differences between males and females in the perception and experience of pain. Research suggests that women are more vulnerable towards experiencing a greater number of pain episodes across the lifespan, in more bodily areas and with greater frequency than men [43].

Therefore, in puberal adolescents we can tackle the variation between and within boys and girls in the experience of visceral pain, headache, musculoskeletal pain, and quality of life $[44,45]$. Investigations focused also on difference between males and females in opioid analgesia, from both experimental and clinical approaches [46]. However, data on pain sensitivity and on analgesic effects of various drugs in male and female prepuberal subjects, in human or laboratory animal species, are still scanty.

\section{POSSIBLE LONG-TERM EFFECTS INDUCED BY PAIN AND DRUG USE}

Possible long-term alterations on nervous system plasticity and on the neonatal programming of endocrine structures induced by stressful experiences, as strong pain or repeated mild pain are, are described in the Introduction paragraph. Such effects, and studies about pharmacological and nonpharmacological tools to prevent or reduce them, are beyond the limits of our paper, and involve also experimental hypotheses which are still far from clinical application, therefore they shall not be dealt with.

Another important topic, namely the development of tolerance or physical dependence with repeated use, is a characteristic feature of all the opioid drugs. Tolerance and dependence are physiological responses seen in all patients, and are not predictors of addiction (hereby we remember that addiction is a behavioural pattern characterized by compulsive use of a drug and overwhelming involvement with its procurement and use). These processes, tolerance, dependence and addiction, appear to be quite distinct. For example, cancer pain often requires prolonged treatment with high doses of opioids, leading to tolerance and dependence. Yet, abuse in this setting is very unusual, whereas abuse is seen when opioids are assumed for non-medical purposes. Therefore, neither the presence of tolerance and dependence, nor the fear that they may develop should ever interfere with the appropriate use of opioids [47]. 


\section{LONG-TERM PAIN AND PAIN DURING TERMINAL CARE}

It is suggested that in a health district of 250000 people, with a child population of approximately 50000, in one year, 50 children are likely to have a life-limiting condition, about half of whom will need active palliative care at any one time, and 5 are likely to die of

a life-limiting condition, and of these,

- 2 will die from cancer

- 1 of heart disease

- 2 of other life-limiting condition

(modified from Anonymous, 1997) [28].

Existing knowledge provides a basic approach for relieving cancer pain and chronic pain that can be implemented in developed and developing countries alike. Children with cancer or with severe life-limiting conditions do not need to suffer unrelieved pain. Effective pain management and palliative care are among major priorities of the WHO cancer programme. Pain management must begin when a child is first diagnosed with cancer and must continue throughout the course of the illness. Analgesic and anaesthetic drug therapies are essential in controlling pain and should be combined with appropriate psychosocial, physical, and supportive approaches to this problem [48].

In developed countries cancer is the leading cause of death from disease in 1-14 year-olds; approximately a figure of $70 \%$ of children can be cured if the disease is diagnosed early and appropriately treated, depending on the diagnosis type and precocity. Most children who live in developing countries do not receive curative therapies: often the disease is advanced by the time of diagnosis and curative therapies are frequently unavailable, or peoples cannot afford them. Countries differ widely in their diagnostic capabilities and reporting systems, however data in developed countries indicate that all children with cancer do experience disease- or treatment-related pain, with more than $70 \%$ of them suffering from severe pain at some point. Although the means exist for its effective relief, children's pain is often not recognized or, if recognized, may be inadequately treated, even when sufficient resources are available $[49,50]$.

In Table $\mathbf{4}$ are depicted the expenses for opioid drugs in 11 of the European Countries, normalized in percent over the total drugs expense, in the whole population. Opioid drugs expenses are good parameters indicating the quality of cancer chronic pain therapy. Ratio between the highest users (Ireland and UK) and lowest users (Italy and Portugal) is in the order of 7.3.

Unrelieved pain places a heavy burden on children and families, and also on medical structures:

Children become afraid of actual and future pain, and develop mistrust and fear of hospitals, medical staff and treatment procedures.

- $\quad$ Parents and other relatives often feel angry and distrustful towards the medical system, and experience depression and guilt about being unable to prevent the pain.
Table 4. Opioid Drugs Expenses in European Countries (Expressed in \% of Total Expense for all Drugs)

\begin{tabular}{|l|}
\hline 1) Ireland 2.17 \\
\hline 2) UK 2.05 \\
\hline 3) Germany 1.89 \\
\hline 4) Austria 1.63 \\
\hline 5) France 1.52 \\
\hline 6) Finland 0.74 \\
\hline 7) Spain 0.73 \\
\hline 8) Belgium 0.69 \\
\hline 9) Greece 0.51 \\
\hline 10) Italy 0.30 \\
\hline 11) Portugal 0.28 \\
\hline
\end{tabular}

(From WHO, 1990) [40].

- $\quad$ Poorly managed pain affects health careworkers: it numbs their compassion, creates guilt, and encourages denial that children are suffering.

Comprehensive care of children with cancer or other lifelimiting diseases includes curative therapies, pain management, and symptoms control, plus compassionate support both for the children and for their families. Parents and children require special psychosocial and spiritual support to help them learn to live with cancer. In some specialized centers, this type of support is provided from the time of diagnosis throughout the child's medical care. Other centers continue to focus exclusively on the medical management of the disease and show little understanding of adequate recognizing and facing all other problems, mainly analgesia, psychosocial and spiritual support. However, such an approach, i.e., global approach to child's needs, is central to the concept of palliative care, and should be part of any health structure which is devoted to admit and cure children. Often there is wide gap between what is known and what is practised; health-care workers may lack information about pain systems, metods of pain assessment, and effective means of relieving mild to severe and cancer pain. Therefore, at least two priorities appear to exist in this field:

First, educational priority. Training programmes for health-care workers should contain essential guidelines for relieving pain in children.

Second, organizative priority. The staff of every hospital and cancer unit should include individuals with expertise in pain management. Moreover, integrated organizative units for palliative care should be recognized as an an integral part of cancer care, and should make provision for psychosocial support for the family, who are the child's primary caregivers. Additional support is essential for the family of a dying child. Specialized home-care agencies, hospices, respite care homes, and palliative care units in hospitals may be considered for further assistance where needed.

Complete understanding of these problems include also pain assessment and pain treatment during the dying process. 
A search of the literature on this subject resulted in only a few publications. However, the last period of life of a child suffering from cancer is of crucial importance not only for the child himself but fur his parents and relatives as well. The way the child dies will remain in the memory of his parents for ever. Multiple problems in management of dying child may arise during the last phase. Once again, a palliative care team consisting of medical and psychosocial staff, cannot avert approaching death, but can make it as peaceful and as free of suffering as possible [51, 52].

\section{REFERENCES}

[1] Anand, K.J.; Hickey, P.R. Pain and its effects in the human neonate and fetus. N. Engl. J. Med., 1987, 317, 1321-1329.

[2] American Academy of Pediatrics. The assessment and management of acute pain in infants, children and adolescents. APS. Bull., 2001, $11,1-12$.

[3] Marin-Padilla, M. Structural organization of the human cerebral cortex prior to the appearance of the cortical plate. Anat. Embryol. (Berl), 1983, 168, 21-40.

[4] Molliver, M.E.; Kostovic, I.; Van Der Loos, H. The development of synapses in cerebral cortex of the human fetus. Brain Res., 1973, 50, 403-407.

[5] Bijlani, V.; Rizvi, T.A.; Wadhwa, S. Development of spinal substrate for nociception in man. NIDA Res. Monogr., 1988, 87, 167179.

[6] Charnay, Y.; Paulin, C.; Chayvialle, J-A.; Dubois, P.M. Distribution of substance P-like immunoreactivity in the spinal cord and dorsal root ganglia of the human foetus and infant. Neuroscience, 1983, 10, 41-55.

[7] Begeot, M.; Dubois, M.P.; Dubois, P.M. Immunologic localization of alpha- and beta-endorphins and beta-lipotropin in corticotropic cells of the normal and anencephalic fetal pituitaries. Cell Tissue Res., 1978, 193, 413-422.

[8] Taddio, A.; Katz, J.; Ilersich, A.L.; Koren, G. Effect of neonatal circumcision on pain response during subsequent routine vaccination. Lancet, 1997, 349, 599-603.

[9] Grunau, R.V.; Whitfield, M.F.; Petrie, H.J. Pain sensitivity and temperament in extremely low-birth-weight premature toddlers and preterm and full-term controls. Pain, 1994, 58, 341-346.

[10] Lidow, M.S. Long-term effects of neonatal pain on nociceptive systems. Pain, 2002, 99, 377-383.

[11] Pieretti, S.; D'amore, A.; Loizzo, A. Long-term changes induced by developmental handling on pain threshold: effects of morphine and naloxone. Behav. Neurosci., 1991, 105, 215-218.

[12] D'amore, A.; Mazzucchelli, A.; Renzi, P.; Loizzo, A. Effect of naloxone on the long-term body weight gain induced by repeated postnatal stress in male mice. Behav. Pharmacol. 1996, 7, 430-436.

[13] Loizzo, A.; Loizzo, S.; Lopez, L.; D’Amore, A.; Renzi, P.; Spampinato, S.; Di Carlo, S.; Bacosi, A.; Zuccaro, P.; Pacifici, R. Naloxone prevents cell-mediated immune alterations in adult mice following repeated mild stress in the neonatal period. $B r . J$. Pharmacol., 2002, 135, 1219-1226.

[14] Loizzo, A.; Capasso, A.; Galietta, G.; Severini, C.; Campana, G.; Spampinato, S. Vas deferens response to selective opioid receptor agonists in adult mice is impaired following postnatal repeated mild stress. Eur. J. Pharmacol., 2003, 458, 201-205.

[15] Franconi, F.; Diana, G.; Fortuna, A.; Galietta, G.; Trombetta, G.; Valentini, G.; Seghieri, G.; Loizzo, A. Taurine administration during lactation modifies hippocampal CA1 neurotransmission and behavioural programming in adult male mice. Brain Res. Bull., 2004, 63, 491-497.

[16] Ruda, M.A.; Ling, Q.D.; Hohmann, A.G.; Peng, Y.B.; Tachibana, T. Altered nociceptive neuronal circuits after neonatal peripheral inflammation. Science, 2000, 289, 628-631.

[17] Besson, J.M. The neurobiology of pain. Lancet, 1999, 353, 16101615.

[18] Fitzgerald, M.; Beggs, S. The neurobiology of pain: developmental aspects. Neuroscientist, 2001, 7, 246-257.

[19] Tollison, C.D.; Satterthwaite, J.R.; Tollison, J.W. Pratical pain management, $3^{\text {rd }}$ ed.; Philadelphia: Lippincott Williams \& Wilkins, 2002.

[20] Emea, Committee for Medicinal Products for Human Use(CHMP): note for guidance on clinical investigation of medicinal products for treatment of nociceptive pain. London, 21 November 2002, CPMP/EWP/612/00

[21] Emea, Committee for Medicinal Products for Human use(CHMP): guidelinee on clinical investigation of medicinal products intended for the treatment of neuropathic pain. London, 18 November 2004, CHMP/EWP/252/03.

[22] Merskey, H.; Bogduk, N. Classification of chronic pain, $2^{\text {nd }}$ ed. Seattle: IASP, 1994, pp. 6-36.

[23] Gaukroger, P.B. Paediatric analgesia. Which drug? Which dose? Drugs, 1991, 41, 52-59.

[24] Adirim, T.A.; Cheng, T.L. Overview of injuries in the young athlete. Sports Med., 2003, 33, 75-81.

[25] White, J.R.; Dalton, H.J. Pediatric trauma: postinjury care in the pediatric intensive care unit. Crit. Care Med., 2002, 30, S478-488.

[26] Slade, G.D. Epidemiology of dental pain and dental caries among children and adolescents. Community Dent. Health, 2001, 18, 219227.

[27] Grazzi, L. Primary headaches in children and adolescents. Neurol. Sci., 2004, 25, S232-233.

[28] Anonymous. A guide to the development of children's palliative care services. Published jointly by Association for Children with Life-threatening or Terminal Conditions and their Families, and Royal College of Paediatrics and Child Health, 1997.

[29] American academy of Pediatrics and Canadian Paediatric society. Prevention and Management of pain and stress in neonate. Pediatrics, 2000, 105, 454-461.

[30] Chiswick ML. Assessment of pain in neonates. Lancet, 2000, 355, 6-8.

[31] Mathew, P.J.; Mathew, J.L. Assessment and management of pain in infants. Postgrad. Med. J., 2003, 79, 438-443.

[32] Royal College of Paediatrics and Child Health. Prevention and Control of pain in children. A manual for health care professionals. London: BMJ, 1997.

[33] Anand, K.J. Consensus Statement for the prevention and management of pain in newborn. Arch. Pediatr. Adolesc. Med., 2001, 155, 173-180.

[34] ANAES. Evaluation et strategies de prise en charge de la douleur aigue en ambulatoire chez l'enfant de un mois à 15 ans. Arch. Pèdiatr., 2001, 8, 420-432.

[35] Finley, G.A.; Mc Grath, P.J. Acute and procedure pain in Infants and children. Progress in pain research and Management. Issue 20. Seattle: IASP Press, 2001.

[36] Sturloni, N.; Garetti, E.; Paolucci, P. The development in the understanding of pain in children. The Suffering Child., 2003 Oct; 4: www.thesufferingchild.net

[37] Maritano, M. Dolore e dolori. Manuale di diagnosi e terapia. CG Edizioni Medico Scientifiche srl, Torino, 2003.

[38] Frank, L.S.; Miaskowski, C. Measurement of neonatal responses to painful stimuli: a research review. J. Pain Symptom Manage., 1997, $14,343-378$.

[39] Duhn, L.J.; Medves, J.M. A systematic integrative review of infant pain assessment tools. Adv. Neonatal Care, 2004, 4, 126-140.

[40] World Health Organization. Cancer pain relief and palliative care: Report of a WHO Expert Committee. World Health Organization, Geneva, Switzerland, 1990.

[41] Jay, S.; Elliot, C.; Katz, E.; Siegel, S. Cognitive-behavioral and pharmacologic interventions for children's distress during painful medical procedures in children. J. Cons. Clin. Psychol., 1987, 55, 860-865.

[42] Smith, J.; Barabasz, A.; Barabasz, M. Comparison of hypnosis and distraction in severely ill children undergoing painful medical procedures. J.Coun. Psychol., 1996, 43, 187-195.

[43] Unruh AM. Gender variations in clinical pain experience. Pain, 1996, 65, 123-167.

[44] Bingefors, K.; Isaacson, D. Epidemiology, co-morbidity, and impact on health-related quality of life of self-reported headache and musculoskeletal pain-a gender perspective. Eur. J. Pain, 2004, 8, 435-450.

[45] Mayer, E.A.; Berman, S.; Chang, L.; Naliboff, B.D. Sex-based differences in gastrointestinal pain. Eur. J. Pain, 2004, 8, 451-463.

[46] Fillingim, R.B.; Gear, R.W. Sex differences in opioid analgesia: clinical and experimental findings. Eur. J. Pain, 2004, 8, 413-425.

[47] Gutstein, H.B.; Akil, H. The pharmacological basis of therapeutics, Goodman\&Gilman's, Eds.; Opioid analgesics, $10^{\text {th }}$ ed.; Mc GrawHill, 2001. 
[48] World Health Organization. Cancer pain relief and palliative care in children: Report of a WHO Expert Committee. World Health Organization, Geneva, Switzerland, 1998.

[49] Magrath, I.; Adde, M.; Shad, A.; Venzon, D.; Seibel, N.; Gootenberg, J.; Neely, J.; Arndt, C.; Nieder, M.; Jaffe, E.; Wittes, R.A.; Horak, I.D. Adults and children with small non-cleaved-cell lymphoma have a similar excellent outcome when treated with the same chemotherapy regimen. J. Clin. Oncol., 1996, 14, 925-934.
[50] Miser, A.W.; Dothage, J.A.; Wesley, R.A.; Miser, J.S. The prevalence of pain in a pediatric and young adult cancer population. Pain, 1987, 29, 73-83.

[51] Merkel, S.; Malviya, S. Pediatric pain, tools, and assessment. $J$. Perianesth. Nurs., 2000, 15, 408-414.

[52] Postovsky, S.; Ben Arush, M.W. Care of a child dying of cancer: the role of the palliative care team in pediatric oncology. Pediatr. Hematol. Oncol., 2004, 21, 67-76.

Received: December 29, 2008

() Loizzo et al.; Licensee Bentham Open.

This is an open access article licensed under the terms of the Creative Commons Attribution Non-Commercial License (http://creativecommons.org/licenses/by-nc/3.0/) which permits unrestricted, non-commercial use, distribution and reproduction in any medium, provided the work is properly cited. 